\title{
Adsorption of Malachite Green From Aqueous Solution Using Hydroxyethyl Starch Hydrogel Improved by Graphene Oxide
}

\section{Alper Onder}

Çanakkale Onsekiz Mart Üniversites - Terzioğlu Kampüsü: Canakkale Onsekiz Mart Universitesi

Mehmet Rıza Kıvanç

Van Yuzuncu Yil University: Van Yuzuncu Yil Universitesi

\section{Seçil Durmuş}

Çanakkale Onsekiz Mart Üniversites - Terzioğlu Kampüsü: Canakkale Onsekiz Mart Universitesi

Pinar llgin ( $\sim$ pinarilgin2014@gmail.com )

Çanakkale Onsekiz Mart Üniversitesi: Canakkale Onsekiz Mart Universitesi

\section{Hava Ozay}

Çanakkale Onsekiz Mart Üniversites - Terzioğlu Kampüsü: Canakkale Onsekiz Mart Universitesi

\section{Ozgur Ozay}

Çanakkale Onsekiz Mart Üniversites - Terzioğlu Kampüsü: Canakkale Onsekiz Mart Universitesi

\section{Research Article}

Keywords: Starch, Graphene oxide, Hydrogel, Adsorption, Malachite green

Posted Date: November 9th, 2021

DOI: https://doi.org/10.21203/rs.3.rs-976656/v1

License: () (1) This work is licensed under a Creative Commons Attribution 4.0 International License.

Read Full License

Version of Record: A version of this preprint was published at Journal of Polymers and the Environment on February 25th, 2022. See the published version at https://doi.org/10.1007/s10924-022-02410-8. 


\section{Abstract}

This study is the first report of the preparation of hydroxyethyl starch (HES) hydrogels rapidly crosslinked with divinyl sulfone in a single step and single pot. To develop the physical and chemical features of hydrogels, Graphene oxide (GO) nanoparticles were combined with the crosslinked HES. In addition to swelling studies, structural characterization of the samples was conducted with a scanning electron microscope (SEM) and transmission electron microscope (TEM), Fourier transform infrared (FTIR) spectroscopy, X-ray diffractometry (XRD), Brunauer-Emmett-Teller (BET) analysis and thermogravimetric analysis (TGA). For the removal of malachite green model dye by GO-HES, the effects of $\mathrm{GO}$ content, solution concentration, temperature, contact duration, dosage and $\mathrm{pH}$ on varying adsorption features were researched. Additionally, adsorption isotherms, kinetic and thermodynamic systematics were analyzed. The maximum adsorption capacity of GO-HES composite hydrogel was found to be $89.3 \mathrm{mg} / \mathrm{g}$ for Langmuir isotherm. The possible adsorption mechanism of the composite hydrogels for malachite green dye involved electrostatic, hydrogen bonding, and $\pi-\pi$ interactions. In addition to reasonable cost and simple synthesis method, the prepared composite materials have potential use in wastewater treatment as adsorbents for the removal of dye from aqueous solutions due to efficient adsorption capacity.

\section{Introduction}

With the rapid industrial development of textile, paper, food, leather and cosmetic industries, dyes are consumed in terrific amounts. These dyes are a serious source of pollution in water masses when discharged above a certain concentration in wastewater. Most dye agents have high toxic, teratogenic, mutagenic and cancerogenic effects $[1,2]$. At the same time, many dyes are difficult to degrade biologically and are more resistant to environmental conditions. For this reason, they form a significant threat to human health and ecology [3]. One of these dyes, malachite green (MG) belongs to the triphenylmethane category. It is a green crystal powder and is a water-soluble cationic dye [4]. Adsorption is chosen more often compared to all other wastewater treatment processes (coagulation-flocculation, photodegradation, membrane filtration, biological degradation, electrolysis, ion exchange, etc.) for water reusability, due to its reasonable costs, efficiency, simple design, ease of use, being insensitive to toxic pollutant materials and not causing harmful agent formation $[1,3,5-8]$.

Hydrogels are three-dimensional insoluble hydrophilic polymer networks that can absorb large amounts of water. Linked to their design, hydrogels can serve in comprehensive and countless applications in a variety of areas from biomedical applications to wastewater treatment applications due to both adjustable features and multifaceted production methods [9-11]. In recent years, due to the need for multifaceted materials, nanocomposite hydrogels with a variety of properties have been developed with the inclusion of different types of metallic (gold, silver and iron oxides), carbon-based (carbon nanotubes, graphene, nanodiamonds) and inorganic/ceramic (hydroxyapatite, silicates and calcium phosphate) nanoparticles or nanostructures within the hydrogel network to improve various properties of hydrogel and its disadvantages $[12,13]$. 
Graphene, one of these nanomaterials researched to date, has attracted the great attention of researchers. Graphene oxide (GO) is a hydrophilic carbonaceous nanomaterial with many functional groups rich in oxygen on the surface (like $\mathrm{COOH},-\mathrm{O}-$ and $-\mathrm{OH}$ ). It is easily dissolved in water and organic solvents. Due to unrivaled features like uncomplicated synthesis process, non-toxic structure, perfect chemical stability, good mechanical features and environmental friendliness, it has received great interest from researchers for applications in a variety of areas $[14,15]$. GO has low cost and provides maximum surface area as an adsorbent for effective removal of pollutants from wastewater [15]. GO nanoparticles suspended in aqueous media have efficient pollutant removal activity at low dosage; however, the efficiency in removing these nanoparticles from the water for reuse is low [16]. To overcome this limitation, GO nanoparticles can be included in a polymer network to provide a composite material that has both broad surface area and ensures reuse of the material. Starch is a common polysaccharide comprised of D-glycose units found in abundant amounts in plants and represents a material with multifaceted and economic potential use in areas like the food industry, agriculture, medication and pharmaceuticals, environment and textile industries. The most interesting features of starch-based hydrogels are their cheapness, easy preparation with reactive, hydrophilic and non-toxic nature, biological compatibility and biological degradability [17]. HES polymers require crosslinking to improve features like stability and sturdiness. In the literature in recent times, there are very few studies about GO-starch-based composites and some of these examined applications as membrane filtering [18], drug delivery system [19] and adsorption [20,21]. Another study reported a nanocomposite comprising starch, polyacrylamide and poly(2-acrylamido-2-methylpropane sulfonic acid) including GO layers for methylene blue adsorption [22].

This study presents a direct single-pot in situ synthesis approach for a graphene oxide-starch nanocomposite (GO-HES) for the first time, for use as an effective, easily prepared and cheap new bioadsorbent for removal of dye from waste. The importance of this study is the inclusion of HES as an intermediate part in suspension to prevent the clustering and precipitation problems of GO, providing a larger pore volume and ensuring reusability. In addition to swelling behavior of the prepared materials, morphology, chemical structure, and crystal features were analyzed with SEM, TEM, FTIR, XRD, BET and TGA, respectively. The synthesized composite hydrogel was researched for potential adsorption of the toxic basic dye-malachite green. The effect of a variety of experimental parameters like solution $\mathrm{pH}$, initial dye concentration, equilibrium contact time, amount of adsorbent and temperature on the process using the synthesized composite hydrogels were examined. Additionally, the process kinetics, isotherms and thermodynamic analysis were performed to explain the adsorption mechanism for data obtained from adsorption studies. Finally, sequential adsorption-desorption cycles were completed to determine the reusability of GO-HES reported in this study.

\section{Materials And Methods \\ 2.1. Materials}


Hydroxyethyl starch (HES, medium MW), divinyl sulfone (DVS, $\geq 96 \%$ ) and graphite were purchased from Sigma-Aldrich chemical company. Malachite green (C.I. 42000) was purchased from Isolab chemicals.

\subsection{Instruments}

A scanning electron microscope (SEM, FEI-QUANTA FEG 250) was used to observe the microstructure of hydrogels. Transmission electron microscopy (TEM) imaging of hydrogels was accomplished using a JEOL TEM-1400-EDX. X-ray diffraction (XRD) studies were carried out with a PANalytical Empyrean device, operating parameters were $\lambda=1.54056 \AA$ at $45 \mathrm{kV}$ and $40 \mathrm{~mA}$. Fourier-transform infrared (FTIR) spectra were recorded on a Perkin Elmer 100 spectrometer device with ATR in the range of $650 \mathrm{~cm}^{-1}-4000$ $\mathrm{cm}^{-1}$. A Perkin Elmer TGA 8000 device (TGA) was employed to analyze thermal degradation of samples, which were heated from $30^{\circ} \mathrm{C}$ to $900^{\circ} \mathrm{C}$ under nitrogen flow at heating rate of $10^{\circ} \mathrm{C} / \mathrm{min}$. The surface areas of the hydrogels were determined by multipoint BET (Quantachrome QuadraSorb SI). UV-VIS absorption spectra were recorded on a T80+UV/VIS Spectrometer, PG Ins. Ltd.

\subsection{Preparations of HES hydrogel}

A HES solution was prepared by dispersing HES in $0.2 \mathrm{~mol} / \mathrm{L} \mathrm{NaOH}$ at a concentration of $50 \mathrm{mg} / \mathrm{L}$, stirred at $600 \mathrm{rpm}$ at room temperature for $120 \mathrm{~min}$. The preparation of the HES hydrogel was completed in a single main step. For this, $2 \mathrm{ml}$ HES solution had $240 \mu \mathrm{LVS}$ added as a cross-linker and mixed homogeneously and then transferred to a straw with $5 \mathrm{~mm}$ diameter with the aid of an injector. A few minutes later, gelation occurred. Later, gels were cut to $3 \mathrm{~mm}$ in length. After washing several times during one day in distilled water, they were dried at room temperature and stored for experimental studies.

\subsection{Preparations of GO-HES nanocomposite hydrogel}

Graphene oxide was synthesized from graphite using Hummer's method [23]. The preparation of GO-HES hydrogel was completed in a single main step. For the preparation of the GO-HES composites, firstly, GO powder $(1.29 ; 3.78 ; 6.14 ; 8.39 ; 10.54$, w\%) was distributed ultrasonically in $2 \mathrm{~mL}$ HES solution for 1 hour. Later, after $240 \mu$ IVS was added, it was mixed homogeneously and transferred to a straw with $5 \mathrm{~mm}$ diameter with the aid of an injector. A few minutes later, gelation occurred. Later gels were cut to $3 \mathrm{~mm}$ in length. After washing several times during one day in distilled water, they were dried at room temperature and stored for experimental studies.

\subsection{Swelling studies}

According to previous reports, the swelling behavior (S) of hydrogels was tested in distilled water $[24,25]$.

$$
S \%=\left(M_{t}-M_{0}\right) / M_{0} x 100(1)
$$

$M_{0}$ and $M_{t}$ are the dry weight of the hydrogel initially and the weight of the swollen hydrogel at regular time intervals or after equilibrium swelling is reached.

\subsection{Batch adsorption experiments}


To determine the batch adsorption features for $M G$ adsorption affected by different experimental factors, adsorption experiments were completed with defined durations, definite volume $(10 \mathrm{ml})$ of $\mathrm{MG}$ solution in $50 \mathrm{~mL}$ centrifuge tubes. Various adsorption conditions of initial feed concentration of dye solution (25; $50 ; 75 ; 125 ; 250 \mathrm{mg} / \mathrm{L})$, pH of dye solution $(2.0 ; 3.0 ; 4.5 ; 5.5 ; 6.5 ; 7.5 ; 8.5 ; 10.0)$, dosage of composite hydrogel $(10 ; 20 ; 40 ; 65 \mathrm{mg} / \mathrm{ml})$, and temperature of dye solution $\left(21 ; 37 ; 50^{\circ} \mathrm{C}\right)$ were investigated. After adsorption, the MG amount remaining in solution was measured with a UV-Vis spectrophotometer at 616 $\mathrm{nm}$ maximum wavelength. The MG adsorption capacity $\mathrm{Q}(\mathrm{mg} / \mathrm{g})$ and $M G$ removal percentage ratio ( $\mathrm{R} \%$ ) were calculated using equations (2) and (3), respectively [25].

$$
\begin{gathered}
Q_{a d s}\left(\frac{m g}{g}\right)=\left(C_{0}-C_{t}\right) V / M(2) \\
R \%=\left(C_{0}-C_{t}\right) / C_{t} X 100(3)
\end{gathered}
$$

Here, $C_{0}(m g / L)$ and $C_{t}(m g / L)$ are the $M G$ concentration before the adsorption process and after the adsorption process, respectively. $\mathrm{V}(\mathrm{mL})$ is the $M G$ solution volume and $\mathrm{M}(\mathrm{mg})$ is the mass of the adsorbent.

\subsection{Desorption and reusability}

The adsorbent was first saturated in an MG solution $(25 \mathrm{mg} / \mathrm{L})$ for 24 hours duration for desorption and reuse studies. The adsorbent dosage was $2 \mathrm{mg} / \mathrm{mL}$ and the solution $\mathrm{pH}$ was 8.5 . For the desorption studies, the adsorbent was dipped in $0.1 \mathrm{M} \mathrm{HCl}(\mathrm{aq})$ for 24 hours and release of all dye was ensured. Then it was rinsed with distilled water. After the hydrogels were dried, they were used again. The same adsorbent was used for adsorption and desorption three times repeatedly. The MG desorption capacity Q $(\mathrm{mg} / \mathrm{g})$ and desorption efficiency percentage were calculated using equations (4) and (5), respectively [26].

$$
\begin{gathered}
Q_{\text {des }}\left(\frac{m g}{g}\right)=\left(C_{f}\right) V / M(4) \\
\text { Desorption } \%=\left(Q_{d e s} / Q_{a d s}\right) X 100(5)
\end{gathered}
$$

Here, $C_{f}(m g / L)$ is the $M G$ concentration in solvent. $V(m L)$ is the $M G$ solvent volume and $M(m g)$ is the mass of the adsorbent.

\section{Results And Discussion}

During the preparation of hydrogels, the double vinyl group of DVS, a hydrophobic molecule with low water affinity, was reacted with the hydroxyl groups of HES to form a three-dimensional network and cross-linker points formed through covalent bonding. This reaction occurs in basic media where the main hydroxyl groups are ionized and the alkoxide groups provided the formation of ether bonds after attack 
by the DVS pair [27]. During the synthesis of the GO-HES composite hydrogel, GO was firstly homogeneously distributed between the dissolved HES macromolecular chains. Due to the large specific surface area of GO and functional groups containing significant oxygen, HES macromolecular chains can easily hold the $\mathrm{GO}$ surface through hydrogen bonding and prevent the precipitation of $\mathrm{GO}$ within the solution [28]. The reaction mechanisms proposed for the GO-HES hydrogel and HES hydrogel are given in Figure 1.

\subsection{Characterization of hydrogel}

The surface morphology of the HES hydrogel and GO-HES composite hydrogel was measured using an SEM and images are shown in Figure 2. The images in Figure 2 show the hydrogel has a crosslinked three-dimensional network structure. GO appears to be homogeneously distributed within the hydrogel matrix in Figure 1. Due to the interaction of GO with HES active chains, agglomeration and cluster formation due to GO were not observed in the GO-HES composite hydrogel; thus, the stabilized network structures were preserved. Additionally, to further examine the GO-HES composite hydrogel morphology, TEM images were obtained. Figure 3 shows the surface with pore cavities in TEM micrographs. The layered structure formed by GO nano-leaves located within the network can be observed.

TGA measurements were completed to provide additional proof of the presence of GO in the GO-HES structure and to investigate thermal stability behavior and results are shown in Figure 4. The results show that the hydrogels have two degradation stages. For the HES hydrogel, the main degradation occurs with $90 \%$ mass loss in the temperature interval $200-400^{\circ} \mathrm{C}$. For the GO-HES hydrogel, the main degradation occurs from $300-350{ }^{\circ} \mathrm{C}$ with nearly $70 \%$ mass loss. Here, the degradation may be due to the breakage of the polymer chains and the separation of the crosslinked network. Additionally, the HES hydrogel undergoes a second degradation from $400-750^{\circ} \mathrm{C}$ with nearly $10 \%$ mass loss. For the GO-HES hydrogel, the second degradation occurs from $400-850{ }^{\circ} \mathrm{C}$ with nearly $25 \%$ mass loss. The composite hydrogel obtained by the inclusion of GO particles within the HES hydrogel network was increased thermal stability. This may be associated with the improved physical interactions in the hydrogel network.

The XRD models for HES and GO-HES hydrogels are shown in Figure 5. The XRD peaks for GO-HES composite hydrogels display larger differences than HES hydrogels. On the XRD patterns, the HES hydrogel has a range of strong characteristic reflection peaks showing a definite crystal structure, while the GO-HES only has a broad refractive peak at $2 \theta=18.5^{\circ}$, indicating low crystalline and amorphous structure, as seen in Figure 2. There are fewer reflection peaks due to the $G O$ content significantly reducing the intensity of reflection peaks of HES hydrogels in the GO-HES composite hydrogels. Thus, the regularity of the polymer macromolecular chains is destroyed by the addition of GO $[29,30]$.

The FTIR spectra for the (a) unmodified pure HES, (b) cross-linker DVS, (c) GO particles, (d) HES hydrogel crosslinked with DVS and (e) GO-HES composite hydrogel are shown in Figure 6. The distinctive peaks at 1284 and $1105 \mathrm{~cm}^{-1}$ belonging to crosslinked HES hydrogel are attributed to strong asymmetric and symmetric stretching vibrations of the sulfone $(\mathrm{O}=\mathrm{S}=0)$ group [31]. In the GO-HES composite hydrogel, 
the characteristic peaks at 3483,1387 and $1017 \mathrm{~cm}^{-1}$ indicate the presence of stretching of $\mathrm{O}-\mathrm{H}, \mathrm{C}-\mathrm{H}$ (ring) and C-O-C groups [32]. Due to the overlapping of these peaks belonging to GO and HES, the peak signals are essentially increased. The results show that the hydrogel and composite hydrogel were successfully obtained.

The pore volume distributions for the HES hydrogel and GO-HES composite hydrogel were determined using Brunauer-Emmett Teller (BET) analysis. According to the analysis results, when GO is added, the surface area rose from 1.843 to $2.094 \mathrm{~m}^{2} / \mathrm{g}$; additionally, the mean pore size for HES and GO-HES was 4.23 and $6.54 \mathrm{~nm}$. The addition of the GO nanolayer during hydrogel formation transformed it into a nanolayer structure with great intersecting pores; thus, there was an increase in the hydrogel porosity and surface area of the composite hydrogels.

Figure 7a shows the effect of the amount of GO particles in the composite hydrogel network on equilibrium swelling values. The swelling ratio of the hydrogel increased as the $\mathrm{GO}$ amount increased. The reason for this is that the increase in oxygen functional groups from GO in the network structure developed the hydrophilic nature of the hydrogel and allowed the hydrogel to absorb more water [33]. Figure 7b shows the swelling curves against time for the hydrogel and composite hydrogel. The swelling ratio for the hydrogels rapidly increased in the first 5 minutes and 1 hour later, equilibrium was reached. Due to the presence of other functional groups provided by GO, the GO-HES composite hydrogels had a higher swelling ratio than the HES hydrogel. Figure 7c shows the equilibrium swelling values under different $\mathrm{pH}$ conditions. In neutral and basic $\mathrm{pH}$ media, an increase in ionized carboxyl groups on GO particles within the composite hydrogel network and the anion-anion repulsive forces cause an increase in osmotic pressure in the composite hydrogels [34]. For this reason, swelling values increase with the increase in $\mathrm{pH}$ values.

\subsection{Adsorption studies of composite hydrogel}

For MG dye adsorption, the HES hydrogel and the effect of different proportions of GO content within the GO-HES composite hydrogel were researched and the results obtained are given in Figure 8a. The experiments were completed at the original $\mathrm{pH}$ (4.5) of the solution (no pH adjustment) in $10 \mathrm{~mL} \mathrm{MG}$ solution $(25 \mathrm{mg} / \mathrm{L})$ at room temperature $\left(21^{\circ} \mathrm{C}\right)$ with $24 \mathrm{~h}$ contact time and $2 \mathrm{mg} / \mathrm{mL}$ adsorbent dosage. In the Figure, with the increase in $\mathrm{GO}$ content of composite hydrogels, the removal of MG dye increased significantly compared with HES hydrogel. The dye removal percentage for the HES hydrogel was $13.2 \%$, while the removal percentage for the composite hydrogel containing $10.54 \% \mathrm{GO}$ was $57.6 \%$. These results may be linked to the increase in the number of functional groups in the network structure with the inclusion of GO particles which contain many carboxylic groups in the HES hydrogel. When the GO content of the composite hydrogel rises above $8.39 \%$, there is no severe change observed in the adsorption efficiency. This may be due to less usability of the active sites in the network structure for binding to MG dye molecules. For this reason, adsorption studies continued with HES hydrogels containing $8.39 \% \mathrm{GO}$. Similar results were obtained by Eltaweil using carboxymethyl cellulose/carboxylated graphene oxide composite microbeads for methylene blue adsorption [35]. 
The effect of GO-HES composite hydrogel dosage on MG dye adsorption was researched using adsorbent dosages from 10 to $65 \mathrm{mg}$ and the results are plotted in Figure 8b. Experiments were completed at the original $\mathrm{pH}$ (4.5) of the solution (no $\mathrm{pH}$ adjustment) with $10 \mathrm{~mL} \mathrm{MG}$ solution ( $25 \mathrm{mg} / \mathrm{L}$ ) at room temperature with $24 \mathrm{~h}$ contact duration. With the increasing adsorbent dosage, the removal percentage of MG increased in stages and then reduced slightly and remained constant. This result may be due to the increase in active sites on the adsorbent due to the increase in adsorbent amount while dye concentration remained fixed. Similar results were reported in previous studies [36, 37].

Solution $\mathrm{pH}$ is accepted as an important adsorption parameter affecting the surface charge of the adsorbent. For this reason, the effect of $\mathrm{pH}$ on removal \% for adsorption of $\mathrm{MG}$ dye is shown in Figure 8c. Experiments were completed with $\mathrm{pH}$ varying from 2 to 10 , in $\mathrm{MG}$ solution $(25 \mathrm{mg} / \mathrm{L})$ at room temperature with $24 \mathrm{~h}$ contact duration and $2 \mathrm{mg} / \mathrm{mL}$ adsorbent. As shown in Figure, as solution $\mathrm{pH}$ increased in stages from 2 to 10 , the adsorption removal \% increased from 34 to $90 \%$. The adsorption efficiency significantly increased with $\mathrm{pH}$ and later reached equilibrium at $\mathrm{pH}$ 8.5. This phenomenon is due to reduced electrostatic attraction affinity for cationic MG dye with the fall in $\mathrm{pH}$ values linked to protonation of the carboxylate groups in the composite hydrogels. This causes a fall in adsorption capacity. With the increase in $\mathrm{pH}$ values, the carboxylate groups on the adsorbent were deprotonated and the number of groups with strong negative charge increased. Thus, the electrostatic attraction affinity for cationic MG dye of composite hydrogels may increase and high removal efficiency may be obtained. For MG adsorption studies, the solution $\mathrm{pH}$ was chosen as 8.5. Other new studies reported that the increase in negative charges obtained on the adsorbent surface linked to solution $\mathrm{pH}$ similarly increased adsorption capacity $[16,38,39]$.

The interaction between the MG molecules and GO-HES composite hydrogel surface is shown in Figure 9. Essentially, the positive charge $(=\mathrm{N}+)$ groups on the cationic dye of $\mathrm{MG}$ may interact with the functional groups (COO-) on GO-HES with a negative charge in an alkali medium through electrostatic attraction. Functional groups containing oxygen in the HES structure form a hydrogen bond with amine groups on MG. Additionally, aromatic rings in the MG structure may interact through $\pi-\pi$ interaction with aromatic rings on $\mathrm{GO}[40]$.

Investigation of adsorption kinetics is very important to understand the adsorption equilibrium duration and adsorption rate. To assess the effect of contact duration on adsorption of MG dye on GO-HES composite hydrogel, adsorption experiments were performed in a variety of time intervals from 1 to 30 hours with $2 \mathrm{mg} / \mathrm{mL}$ adsorbent dose, solution $\mathrm{pH} 8.5$, and $125 \mathrm{mg} / \mathrm{L} \mathrm{MG}$ at room temperature. Figure 10a shows the removal of MG by the GO-HES composite hydrogel as a function of contact duration. As shown in the Figure, the adsorption of MG by the adsorbent increases rapidly within the first 10 hours due to the empty active sites on the adsorbent at the start of adsorption. Later, adsorption progressed toward equilibrium slowly and in stages according to the reduction in adsorption sites. As can be seen, the maximum adsorption capacity of $57.5 \mathrm{mg} / \mathrm{g}$ was reached in 30 hours. 
Data obtained in this way were tested for fit to the Lagergren pseudo-first-order and pseudo-second-order models $[20,27]$. The equations, kinetic constants and regression coefficients $\left(R^{2}\right)$ for both models are shown in Table 1. At the same time, the graph for each model is shown in Figure $10(b, c)$. The calculated experimental adsorption capacity was $57.5 \mathrm{mg} / \mathrm{g}$ was found to have a good fit to the theoretical adsorption capacity $59.9 \mathrm{mg} / \mathrm{g}$ in the pseudo-second-order model. Additionally, the pseudo-second-order model showed a higher $\mathrm{R}^{2}$ value compared to other models (0.985). Thus, adsorption of MG dye on the GO-HES composite hydrogel surface was concluded to abide by the pseudo-second-order model. 
Table 1

Isotherm, kinetic and thermodynamic parameters for MG adsorption onto composite hydrogel at $294 \mathrm{~K}$.

\begin{tabular}{|c|c|c|c|c|}
\hline $\begin{array}{l}\text { Isotherm/kinetic/thermodynamic } \\
\text { models }\end{array}$ & Linear equations & Plot & Parameters & $\mathrm{R}^{2}$ \\
\hline Langmuir Isotherm & $\frac{\mathrm{C}_{\mathrm{e}}}{\mathrm{Q}_{\mathrm{e}}}=\frac{1}{\mathrm{~K}_{\mathrm{L}} \mathrm{Q}_{\mathrm{m}}}+\frac{\mathrm{C}_{\mathrm{e}}}{\mathrm{Q}_{\mathrm{m}}}$ & $\begin{array}{l}\mathrm{Ce} / \mathrm{Q}_{\mathrm{e}} \\
v s \mathrm{C}_{\mathrm{e}}\end{array}$ & $\begin{array}{l}\mathrm{K}_{\mathrm{L}}(\mathrm{L} / \mathrm{mg})= \\
0.21 \\
\mathrm{Q}_{\mathrm{m}}(\mathrm{mg} / \mathrm{g})= \\
89.3\end{array}$ & 0.995 \\
\hline Freundlich Isotherm & $\ln Q_{e}=\ln K_{F}+\frac{\ln C_{e}}{n}$ & $\begin{array}{l}\ln Q_{e} \\
v s \\
\ln C_{e}\end{array}$ & $\begin{array}{l}\mathrm{K}_{\mathrm{F}}(\mathrm{mg} / \mathrm{g})= \\
22.84 \\
1 / \mathrm{n}=0.31\end{array}$ & 0.979 \\
\hline Pseudo-first-order kinetic & $\ln \left(\mathrm{Q}_{\mathrm{e}}-\mathrm{Q}_{\mathrm{t}}\right)=\ln \mathrm{Q}_{\mathrm{e}}-\mathrm{K}_{1} \mathrm{t}$ & $\begin{array}{l}\ln \left(\mathrm{Q}_{e^{-}}\right. \\
\left.\mathrm{Q}_{\mathrm{t}}\right) v s \\
\mathrm{t}\end{array}$ & $\begin{array}{l}\mathrm{K}_{1}\left(\mathrm{~h}^{-1}\right)= \\
0.192 \\
\mathrm{Q}_{\mathrm{e}}(\mathrm{mg} / \mathrm{g})= \\
75.7\end{array}$ & 0.967 \\
\hline Pseudo-second-order kinetic & $\frac{1}{Q_{\mathrm{t}}}=\frac{1}{\mathrm{~K}_{2} \mathrm{Q}_{\mathrm{e}}^{2}}+\frac{1}{\mathrm{Q}_{\mathrm{e}}}$ & $\begin{array}{l}1 / Q_{t} \\
v s 1 / t\end{array}$ & $\begin{array}{l}\mathrm{K}_{2} \\
\left(\mathrm{~g} \cdot \mathrm{mg}^{-1} \cdot \mathrm{h}^{-1}\right) \\
=3.8 \times 10^{-3} \\
\mathrm{Q}_{\mathrm{e}}(\mathrm{mg} / \mathrm{g})= \\
59.9\end{array}$ & 0.985 \\
\hline Thermodynamic models & $\begin{array}{l}K_{d}=\left(C_{0}-C_{e}\right) / C_{e} \\
\ln K_{d}=\left(\frac{\Delta S^{\circ}}{R}-\frac{\Delta H^{\circ}}{R T}\right) \\
\Delta G^{\circ}=\Delta H^{\circ}-T \Delta S\end{array}$ & $\begin{array}{l}\ln \mathrm{K}_{\mathrm{d}} \\
v s \\
1 / \mathrm{T}\end{array}$ & $\begin{array}{l}\Delta \mathrm{G}^{\circ}(\mathrm{kj} / \mathrm{mol}) \\
=-3.3^{\circ} \\
\Delta \mathrm{S}^{\circ} \\
{[\mathrm{j} /(\mathrm{mol} . \mathrm{K})]=} \\
84.1 \\
\Delta \mathrm{H}^{\circ}(\mathrm{kj} / \mathrm{mol}) \\
=21.5\end{array}$ & 0.854 \\
\hline
\end{tabular}

$Q_{m}$ is relevant with maximum adsorption capacity. $C_{e}(m g / L)$ is the equilibrium concentration of dye solution. $\mathrm{K}_{\mathrm{L}}, \mathrm{K}_{\mathrm{F}}$ and $\mathrm{n}$ are isotherm parameters characterizing Langmuir constant, Freundlich constant, and intensity, respectively. $\mathrm{K}_{1}, \mathrm{~K}_{2}$ are kinetic parameters characterizing rate constants for the pseudo-first-order and the pseudo-second-order model. $\Delta \mathrm{G}^{\circ}, \Delta \mathrm{S}^{\circ}, \Delta \mathrm{H}^{\circ}, \mathrm{R}, \mathrm{T}$ and $\mathrm{Kd}$ are thermodynamic parameters characterizing the standard free energy, standard entropy, standard enthalpy, universal gas constant, temperature (K) and equilibrium constant.

Measurements were performed with solutions containing different initial dye concentrations to research the effect of initial dye concentration on adsorption capacity. Adsorption experiments were completed with varying initial feed concentrations using $2 \mathrm{mg} / \mathrm{mL}$ adsorbent dose and solution $\mathrm{pH}$ 8.5. At a fixed temperature, the correlation between MG dye initial concentration with GO-HES composite hydrogel equilibrium adsorption capacity is shown in Figure 11 (a). As seen in Figure 8a, with the increase in initial dye concentration from 25.0 to $250.0 \mathrm{mg} / \mathrm{L}$, the adsorption capacity continuously increased from 12.4 to 
$85.0 \mathrm{mg} / \mathrm{g}$. This is because, at higher dye concentrations, a more attractive force is needed to overcome the mass transfer resistance between the dye solution and adsorbent $[22,41]$.

Isotherm analysis of adsorption provides valuable information about the behavior and interactions between adsorption molecules and adsorbent efficiency. Experimental data were tested with the two classic isotherm models of Langmuir and Freundlich isotherm models. Equations, kinetic constants and regression coefficients $\left(R^{2}\right)$ for both models are shown in Table 1. The Langmuir isotherm model is based on the assumption that adsorption occurs in a single layer on a homogeneous surface, while the Freundlich isotherm model is based on the assumption that adsorption occurs on a multilayered and heterogeneous surface $[20,27]$. The results show the Langmuir model is compatible with the experimental isotherm data compared to the Freundlich model $\left(R^{2}=0.995\right.$ vs. 0.979$)$. Additionally, the calculated experimental adsorption capacity of $85.0 \mathrm{mg} / \mathrm{g}$ fits better with the theoretical adsorption capacity calculated with the Langmuir model of $89.3 \mathrm{mg} / \mathrm{g}$. Thus, it may be assumed that the adsorption mechanism for MG on GO-HES occurs on a homogeneous surface in a single layer.

Experiments were completed at various temperatures, with $125 \mathrm{mg} / \mathrm{L} \mathrm{MG}$ solution ( $\mathrm{pH}$ 8.5) at room temperature with $24 \mathrm{~h}$ contact duration and $2 \mathrm{mg} / \mathrm{mL}$ adsorbent used. The results obtained from adsorption studies completed at 21,37 and $50{ }^{\circ} \mathrm{C}$ are shown in Figure 12a. In parallel with the increase in temperature, there was an increase in interactions at the active adsorption sites and the removal percentage rose from $91.1 \%\left(20^{\circ} \mathrm{C}\right)$ to $97.8 \%\left(50{ }^{\circ} \mathrm{C}\right)$. This result revealed the endothermic nature of the process.

Adsorption thermodynamics provide beneficial information about energy exchange during the adsorption process. Experimental data were fitted to the Van't Hoff equation. The equations, constants and regression coefficients $\left(R^{2}\right)$ related to this are shown in Table 1. Considering the $\Delta G^{0}$ values in Table 1 , the adsorption of MG on GO-HES can be said to be spontaneous and dominated by physical interactions [42]. Additionally, the positive $\Delta \mathrm{H}^{0}$ value confirms the endothermic nature of the adsorption process, supporting the increase in $M G$ adsorption with the increase in temperature.

In recent times, many different adsorbents with varying structures and compositions containing GO were prepared and used for the removal of a variety of dyes from wastewater. For this reason, the adsorption of MG dye on the GO-HES composite hydrogel prepared in this study was compared with some adsorbents in the literature. Some of those, the calculated maximum adsorption capacity values of starch-graft-poly(acrylamide)/graphene oxide/hydroxyapatite nanocomposite hydrogel, $\mathrm{Fe}_{3} \mathrm{O}_{4} @ \mathrm{SiO}_{2}-$ graphene oxides core-shell magnetic microspheres, magnetic carboxymethyl functionalized chitosangraphene oxide composite, graphene oxide/aminated lignin aerogels were 297, 265.87, 289.1 and 113.5 $\mathrm{mg} / \mathrm{g}$, respectively [43-46]. The results show that the GO-HES composite hydrogel $\left(Q_{\text {max,cal }}=89.3 \mathrm{mg} / \mathrm{g}\right)$ may compete with other adsorbents and has efficient dye removal activity.

In order to be an effective and potential adsorbent for the removal of dyes, the reuse of the adsorbent is as important as the efficient removal of dyes in both environmental and industrial terms. After three

Page $11 / 26$ 
consecutive cycles, the removal efficiency for MG remained above $90 \%$ (Figure 12b). Results revealed that the composite hydrogel is a suitable reusable adsorbent to remove MG from aqueous solutions.

\section{Conclusion}

Hydroxyethyl starch hydrogel and hydroxyethyl starch-graphene oxide (HES-GO) nanocomposite hydrogel were prepared in one step in a simple process using divinyl sulfone as a cross-linker. The properties of the developed hydrogels were characterized in detail and their effectiveness in removing malachite green from aqueous solution was investigated. SEM and TEM analyzes showed that the hydrogels have a porous and crosslinked 3-D network structure. The low swelling capacity showed the benefit of using it as an adsorbent. Experimental adsorption studies have shown that dye adsorption at a dosage of $2 \mathrm{mg} / \mathrm{ml}$ adsorbent at $24 \mathrm{~h}$ and basic $\mathrm{pH}$ has a maximum adsorption capacity of $85.0 \mathrm{mg} / \mathrm{g}$ at $25^{\circ} \mathrm{C}$. In addition, the adsorption kinetics is compatible with the pseudo-second-order kinetic model and the adsorption mechanism is compatible with the Langmuir isotherm model. The desorption experiment with $0.1(\mathrm{M})$ hydrochloric acid revealed that the effect of repeated use is high, and the adsorbents used can be fully recovered. Hence, HES-GO hydrogel is an easily prepared, environmentally friendly and economical adsorbent that can efficiently remove dyes from aqueous solutions.

\section{Declarations}

\section{Disclosure statement}

No potential conflict of interest was reported by the authors.

\section{References}

1. Shindhal T, Rakholiya P, Varjani S, Pandey A, Ngo HH, Guo W, Ng HY, Taherzadeh MJ (2021) A critical review on advances in the practices and perspectives for the treatment of dye industry wastewater. Bioengineered 12(1):70-87. https://doi.org/10.1080/21655979.2020.1863034

2. Khan S, Malik A (2014) Environmental and Health Effects of Textile Industry Wastewater. In: Malik A, Grohmann E, Akhtar R (eds) Environmental Deterioration and Human Health. Springer Netherlands, Dordrecht, pp 55-71. https://doi.org/10.1007/978-94-007-7890-0

3. Carmen Z, Daniel S (2012) Textile Organic Dyes - Characteristics, Polluting Effects and Separation/Elimination Procedures from Industrial Effluents - A Critical Overview, in: T. Puzyn (Ed.), Organic Pollutants Ten Years After the Stockholm Convention - Environmental and Analytical Update, InTech. https://doi.org/10.5772/32373

4. Raval NP, Shah PU, Shah NK (2017) Malachite green "a cationic dye" and its removal from aqueous solution by adsorption. Appl Water Sci 7:3407-3445. https://doi.org/10.1007/s13201-016-0512-2

5. Disli E, Ozturk D, Aladağ E (2021) Utilizing mining dam bottom sludge as a novel adsorbent for AuO removal from wastewaters: Batch and column studies. J Mol Liq 338(15):116644. 
https://doi.org/10.1016/j.molliq.2021.116644

6. Ozturk D, Dagdas E, Fil BA, Bashir MJ (2021) Central composite modeling for electrochemical degradation of paint manufacturing plant wastewater: One-step/two-response optimization. Environ Tech Innov 21:101264. https://doi.org/10.1016/j.eti.2020.101264

7. Ahmad A, Mohd-Setapar SH, Chuong CS, Khatoon A, Wani WA, Kumar R, Rafatullah M (2015) Recent advances in new generation dye removal technologies: novel search for approaches to reprocess wastewater. RSC Adv 5:30801-30818. https://doi.org/10.1039/C4RA16959J

8. Godiya CB, Martins Ruotolo LA, Cai W (2020) Functional biobased hydrogels for the removal of aqueous hazardous pollutants: current status, challenges, and future perspectives. J Mater Chem A 8:21585-21612. https://doi.org/10.1039/D0TA07028A

9. Mahinroosta M, Jomeh Farsangi Z, Allahverdi A, Shakoori Z (2018) Hydrogels as intelligent materials: A brief review of synthesis, properties and applications. Mat Today Chem 8:42. https://doi.org/10.1016/j.mtchem.2018.02.004

10. Sinha V, Chakma S (2019) Advances in the preparation of hydrogel for wastewater treatment: A concise review. J Environ Chem Eng 7(5):103295. https://doi.org/10.1016/j.jece.2019.103295

11. Wang Y (2018) Programmable hydrogels. Biomaterials 178:663-680. https://doi.org/10.1016/j.biomaterials.2018.03.008

12. Han IK, Chung T, Han J, Kim YS (2019) Nanocomposite hydrogel actuators hybridized with various dimensional nanomaterials for stimuli responsiveness enhancement. Nano Convergence 6:18. https://doi.org/10.1186/s40580-019-0188-z

13. Sharma G, Thakur B, Naushad M, Kumar A, Stadler FJ, Alfadul SM, Mola GT (2018) Applications of nanocomposite hydrogels for biomedical engineering and environmental protection. Environ Chem Lett 16:113-146. https://doi.org/10.1007/s10311-017-0671-x

14. Lu H, Zhang S, Guo L, Li W (2017) Applications of graphene-based composite hydrogels: a review. RSC Adv 7:51008-510020. https://doi.org/10.1039/C7RA09634H

15. Zare P, Aleemardani M, Seifalian A, Bagher Z, Seifalian AM (2021) Graphene Oxide: Opportunities and Challenges in Biomedicine. Nanomaterials-Basel 11:1083. https://doi.org/10.3390/nano11051083

16. Zaman A, Orasugh JT, Banerjee P, Dutta S, Ali MS, Das D, Bhattacharya A, Chattopadhyay D (2020) Facile one-pot in-situ synthesis of novel graphene oxide-cellulose nanocomposite for enhanced azo dye adsorption at optimized conditions. Carbohyd Polym 246:116661. https://doi.org/10.1016/j.carbpol.2020.116661

17. Ismail H, Irani M, Ahmad Z (2013) Starch-Based Hydrogels: Present Status and Applications. Int J Polym Mater Polym Biomat 62:411-420. https://doi.org/10.1080/00914037.2012.719141

18. Ambre JP, Dhopte KB, Nemade PR, Dalvi VH (2019) High flux hyperbranched starch-graphene oxide piperazinamide composite nanofiltration membrane. J Environ Chem Eng 7:103300. https://doi.org/10.1016/j.jece.2019.103300 
19. Sattari M, Fathi M, Daei M, Erfan-Niya H, Barar J, Entezami AA (2017) Thermoresponsive graphene oxide - starch micro/nanohydrogel composite as biocompatible drug delivery system. Biolmpacts $\mathrm{BI}$ 7:167-175. https://doi.org/10.15171/bi.2017.20

20. Bhattacharyya A, Banerjee B, Ghorai S, Rana D, Roy I, Sarkar G, Saha NR, De S, Ghosh TK, Sadhukhan S, Chattopadhyay D (2018) Development of an auto-phase separable and reusable graphene oxidepotato starch based cross-linked bio-composite adsorbent for removal of methylene blue dye. Int J Biol Macromol 116:1037-1048. https://doi.org/10.1016/j.ijbiomac.2018.05.069

21. Chen Y, Dai G, Gao Q (2019) Starch Nanoparticles-Graphene Aerogels with High Supercapacitor Performance and Efficient Adsorption. ACS Sustainable Chem Eng 7:14064-14073. https://doi.org/10.1021/acssuschemeng.9b02594

22. Pourjavadi A, Nazari M, Kabiri B, Hosseini SH, Bennett C (2016) Preparation of porous graphene oxide/hydrogel nanocomposites and their ability for efficient adsorption of methylene blue. RSC Adv 6:10430-10437. https://doi.org/10.1039/C5RA21629J

23. Paulchamy A, Arthi G, Lignesh BD (2015) A Simple Approach to Stepwise Synthesis of Graphene Oxide Nanomaterial. J Nanomed Nanotechnol 6:253. https://doi.org/10.4172/2157-7439.1000253

24. Ozay H, llgin P, Ozay O (2021) Novel hydrogels based on crosslinked chitosan with formylphosphazene using Schiff-base reaction. Int J Polym Mater Polym Biomater 70:246. https://doi.org/10.1080/00914037.2019.1706514

25. Kıvanç MR, Ozay O, Ozay H, Ilgin P (2020) Removal of anionic dyes from aqueous media by using a novel high positively charged hydrogel with high capacity. J Disper Sci Technol. https://doi.org/10.1080/01932691.2020.1847658

26. Momina MS, Suzylawati I (2020) Study of the adsorption/desorption of MB dye solution using bentonite adsorbent coating. J Water Pro Eng 34:101155.

https://doi.org/10.1016/j.jwpe.2020.101155

27. Maiz-Fernández S, Pérez-Álvarez L, Ruiz-Rubio L, Pérez González R, Sáez-Martínez V, Ruiz Pérez J, Vilas-Vilela JL (2019) Synthesis and Characterization of Covalently Crosslinked pH-Responsive Hyaluronic Acid Nanogels: Effect of Synthesis Parameters. Polymers 11(4):742. https://doi.org/10.3390/polym11040742

28. Xiao D, He M, Liu Y, Xiong L, Zhang Q, Wei L, Li L, Yu X (2020) Strong alginate/reduced graphene oxide composite hydrogels with enhanced dye adsorption performance. Polym Bull 77:6609-6623. https://doi.org/10.1007/s00289-020-03105-7

29. Ma D, Zhu B, Cao B, Wang J, Zhang J (2016) The Microstructure and Swelling Properties of Poly Acrylic Acid-Acrylamide Grafted Starch Hydrogels. J Macromol Sci Part B 55:1124-1113. https://doi.org/10.1080/00222348.2016.1242552

30. Chen Y, Zhao W, Wang H, Meng X, Zhang L (2018) A novel polyamine-type starch/glycidyl methacrylate copolymer for adsorption of $\mathrm{Pb}(\mathrm{II}), \mathrm{Cu}(\mathrm{II}), \mathrm{Cd}(\mathrm{II})$ and $\mathrm{Cr}(\mathrm{III})$ ions from aqueous solutions. Roy Soc Open Sci 5:180281. https://doi.org/10.1098/rsos.180281 
31. Lai J-Y (2014) Relationship between structure and cytocompatibility of divinyl sulfone cross-linked hyaluronic acid. Carbohyd Polym 101:203-212. https://doi.org/10.1016/j.carbpol.2013.09.060

32. Dai H, Zhang Y, Ma L, Zhang H, Huang $H$ (2019) Synthesis and response of pineapple peel carboxymethyl cellulose-g-poly (acrylic acid-co-acrylamide)/graphene oxide hydrogels. Carbohyd Polym 215:366-376. https://doi.org/10.1016/j.carbpol.2019.03.090

33. Wang M, Chen Y, Khan R, Liu H, Chen C, Chen T, Zhang R, Li H (2019) A fast self-healing and conductive nanocomposite hydrogel as soft strain sensor. Colloid Surface A 567:139-149. https://doi.org/10.1016/j.colsurfa.2019.01.034

34. Ou R, Zhang H, Simon GP, Wang H (2016) Microfiber-polymer hydrogel monolith as forward osmosis draw agent. J Membrane Sci 510:426-430. https://doi.org/10.1016/j.memsci.2016.03.031

35. Eltaweil AS, Elgarhy GS, El-Subruiti GM, Omer AM (2020) Carboxymethyl cellulose/carboxylated graphene oxide composite microbeads for efficient adsorption of cationic methylene blue dye. Int $\mathrm{J}$ Biol Macromol 154:307-318. https://doi.org/10.1016/j.jbiomac.2020.03.122

36. Sirajudheen P, Nikitha MR, Karthikeyan P, Meenakshi S (2020) Perceptive removal of toxic azo dyes from water using magnetic Fe304 reinforced graphene oxide-carboxymethyl cellulose recyclable composite: Adsorption investigation of parametric studies and their mechanisms. Surf Interfaces 21:100648. https://doi.org/10.1016/j.surfin.2020.100648

37. Othman I, Abu Haija M, Kannan P, Banat F (2020) Adsorptive Removal of Methylene Blue from Water Using High-Performance Alginate-Based Beads. Water Air Soil Pollut 231: 396. https://doi.org/doi: $10.1007 / \mathrm{s} 11270-020-04751-3$

38. Ilgin $P$ (2020) High removal of methylene blue dye from aqueous solution by using a novel pectinbased hydrogel. Int J Environ Anal Chem. https://doi.org/10.1080/03067319.2020.1796995

39. Zhao L, Tang P, Sun Q, Zhang S, Suo Z, Yang H, Liao X, Li H (2020) Fabrication of carboxymethyl functionalized $\beta$-cyclodextrin-modified graphene oxide for efficient removal of methylene blue. Arab J Chem 13:7020-7031. https://doi.org/10.1016/j.arabjc.2020.07.008

40. Yao G, Bi W, Liu H (2020) pH-responsive magnetic graphene oxide/poly(NVI-co-AA) hydrogel as an easily recyclable adsorbent for cationic and anionic dyes. Colloids Surfaces A 588:124393. https://doi.org/10.1016/j.colsurfa.2019.124393

41. Qi Y, Yang M, Xu W, He S, Men Y (2017) Natural polysaccharides-modified graphene oxide for adsorption of organic dyes from aqueous solutions. J Colloid Interf Sci 486:84-96. https://doi.org/10.1016/j.jcis.2016.09.058

42. Kıvanç MR, Yönten V (2020) A statistical optimization of methylene blue removal from aqueous solutions by Agaricus Campestris using multi-step experimental design with response surface methodology: Isotherm, kinetic and thermodynamic studies. Surf Interfaces 18:100414. https://doi.org/10.1016/j.surfin.2019.100414

43. Gao L, Wang Y, Yan T, Cui L, Hu L, Yan L, Wei Q, Du B (2015) A novel magnetic polysaccharidegraphene oxide composite for removal of cationic dyes from aqueous solution. New $\mathrm{J}$ Chem 39:2908-2916. https://doi.org/10.1039/C4NJ01792G 
44. Hosseinzadeh H, Ramin S (2018) Fabrication of starch-graft-poly(acrylamide)/graphene oxide/hydroxyapatite nanocomposite hydrogel adsorbent for removal of malachite green dye from aqueous solution. Int J Biol Macromol 106:101-115.

https://doi.org/10.1016/j.jibiomac.2017.07.182

45. Zhang J, Liu M, Liu Z, Yang T, He Q, Yang K, Wang H (2017) Studies of malachite green adsorption on covalently functionalized $\mathrm{Fe}_{3} \mathrm{O}_{4} @ \mathrm{SiO}_{2}$-graphene oxides core-shell magnetic microspheres. J Sol-Gel Sci Technol 82:424-431. https://doi.org/10.1007/s10971-017-4307-1

46. Chen H, Liu T, Meng Y, Cheng Y, Lu J, Wang H (2020) Novel graphene oxide/aminated lignin aerogels for enhanced adsorption of malachite green in wastewater. Colloid Surface A 603:125281. https://doi.org/10.1016/j.colsurfa.2020.125281

\section{Figures}




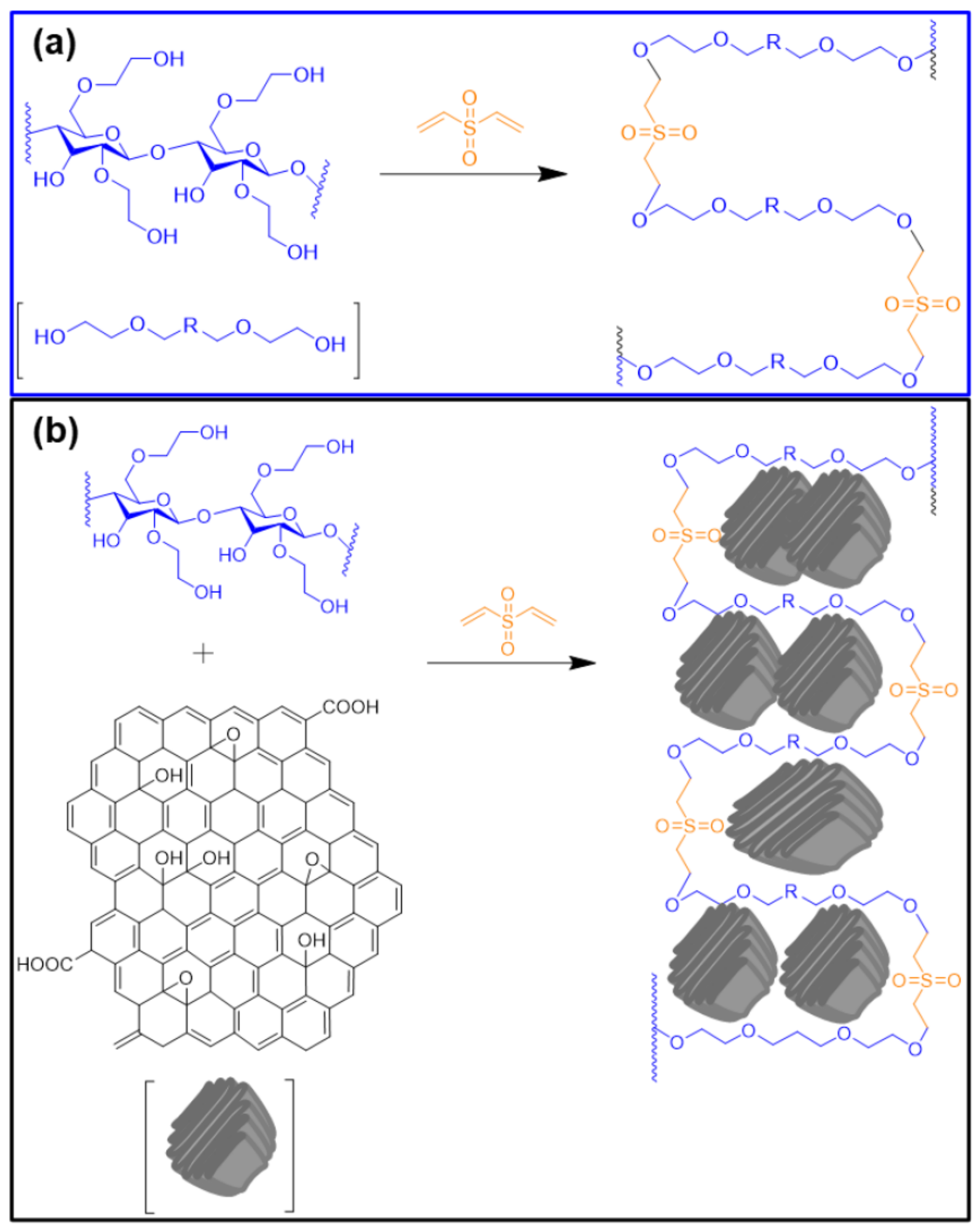

Figure 1

Schematic synthesis mechanism of (a) HES hydrogel and (b) GO-HES nanocomposite hydrogel 


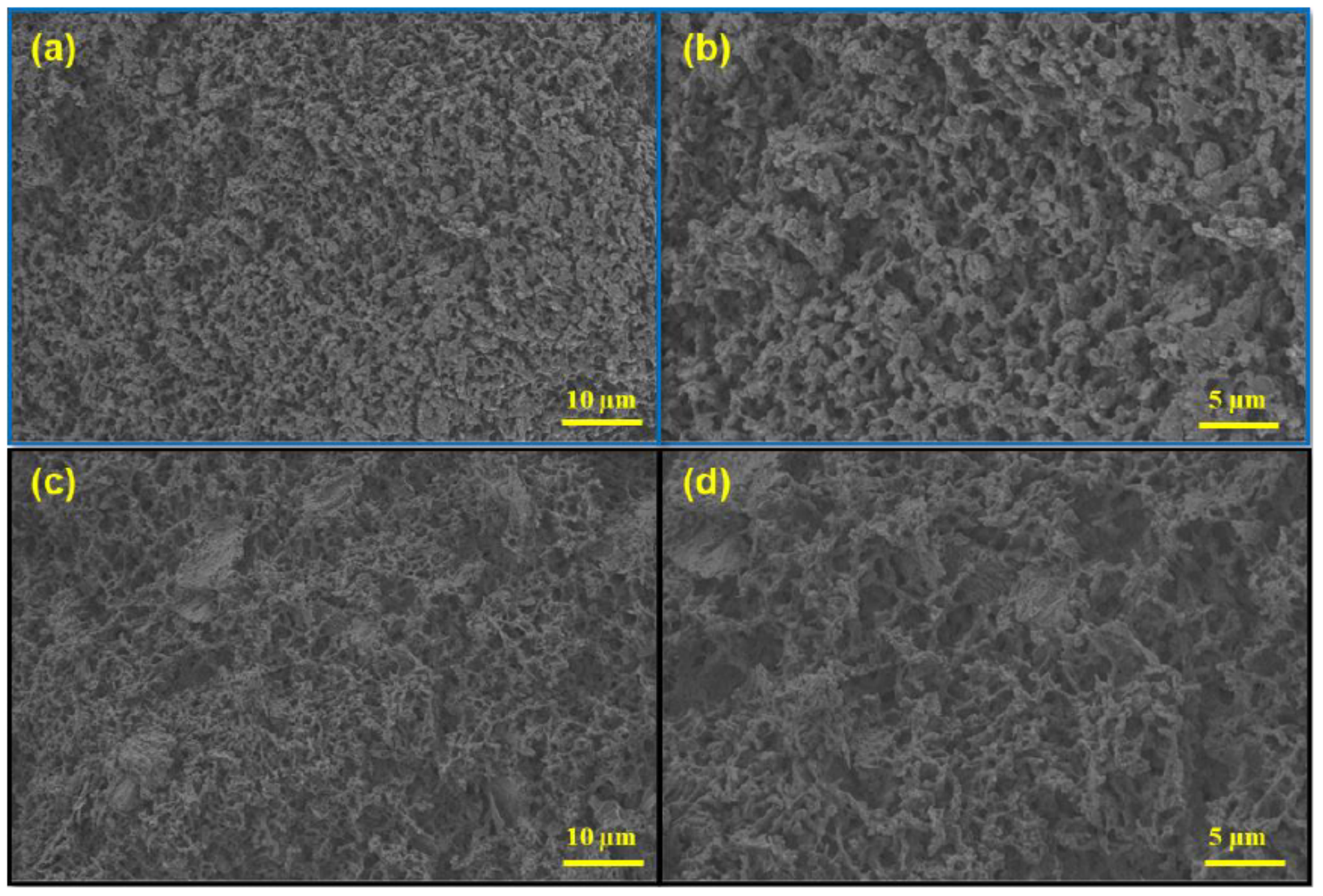

\section{Figure 2}

SEM images of the $(a, b)$ HES hydrogel and $(c, d)$ GO-HES nanocomposite hydrogel for different magnifications $(a, c) \times 5000(c, d) \times 10000$. 


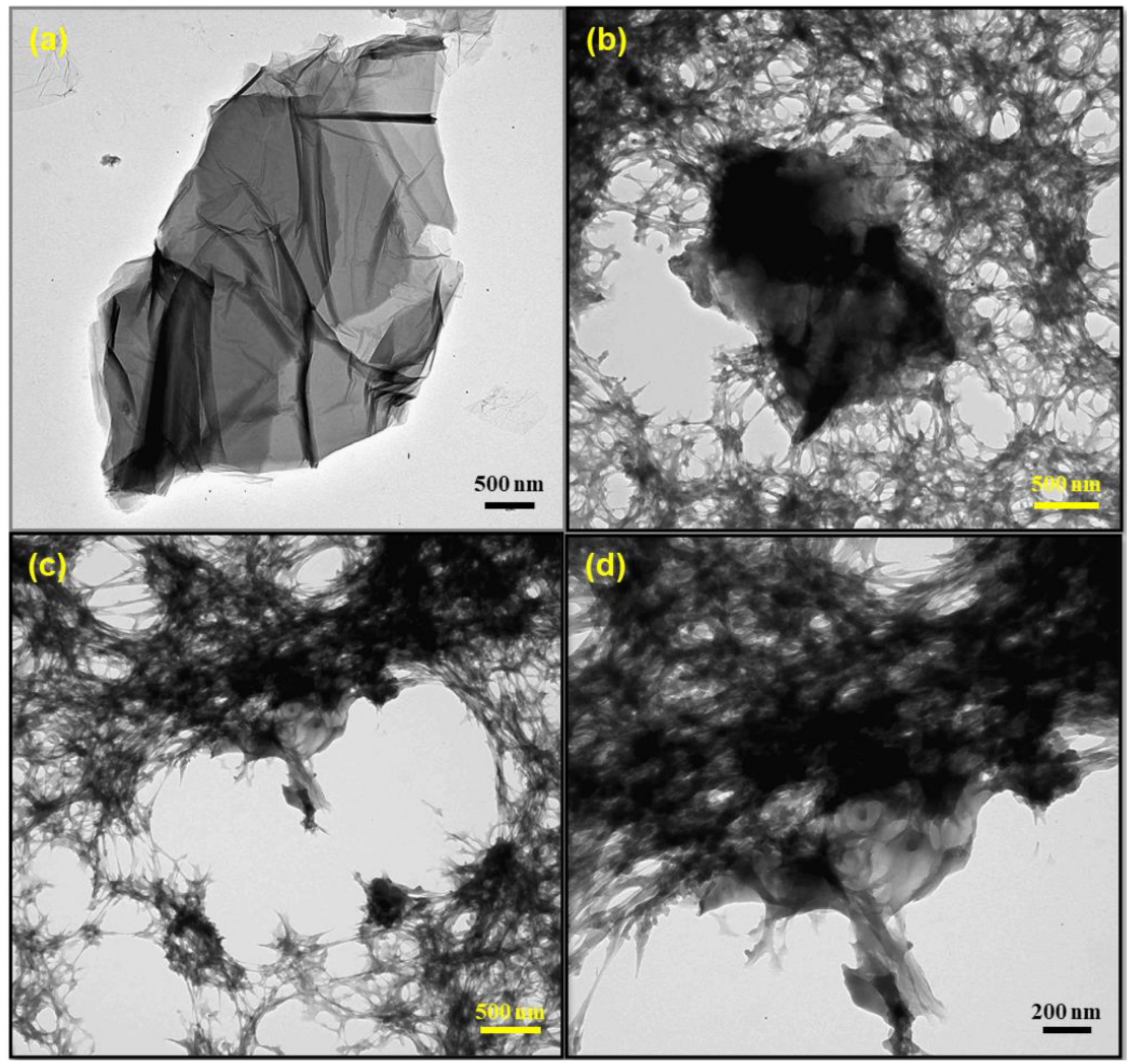

Figure 3

TEM images of the (a) GO particle and (b) GO-HES nanocomposite hydrogel 

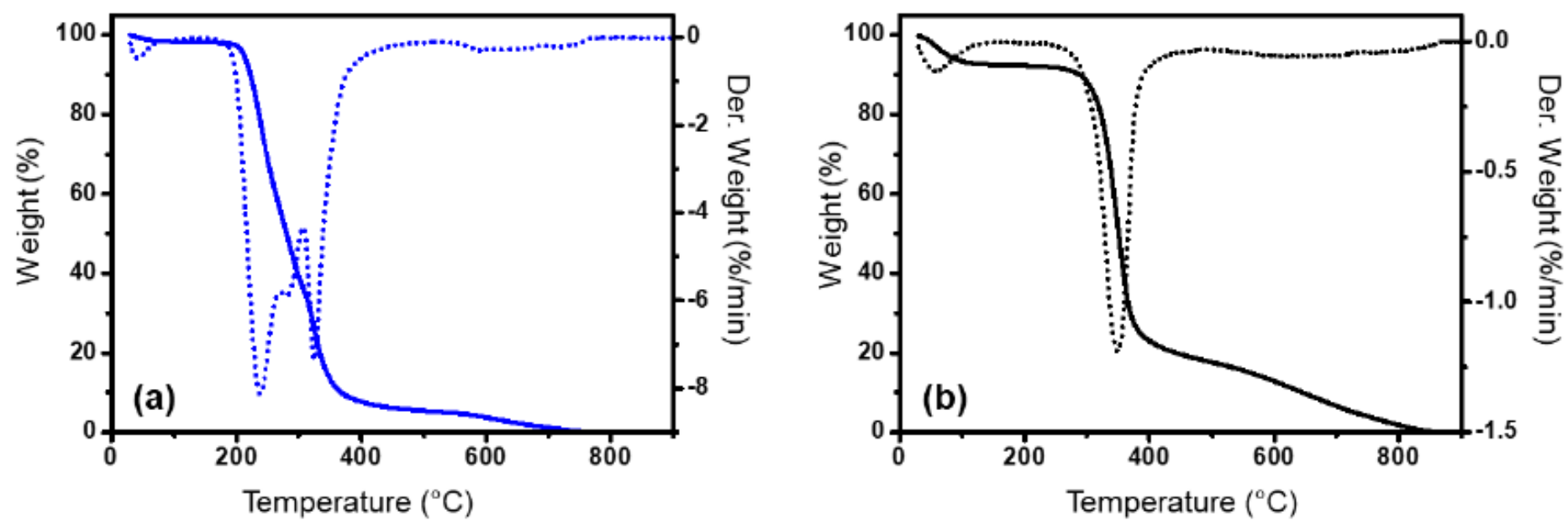

Figure 4

TGA curve of the (a) HES hydrogel and (b) GO-HES nanocomposite hydrogel
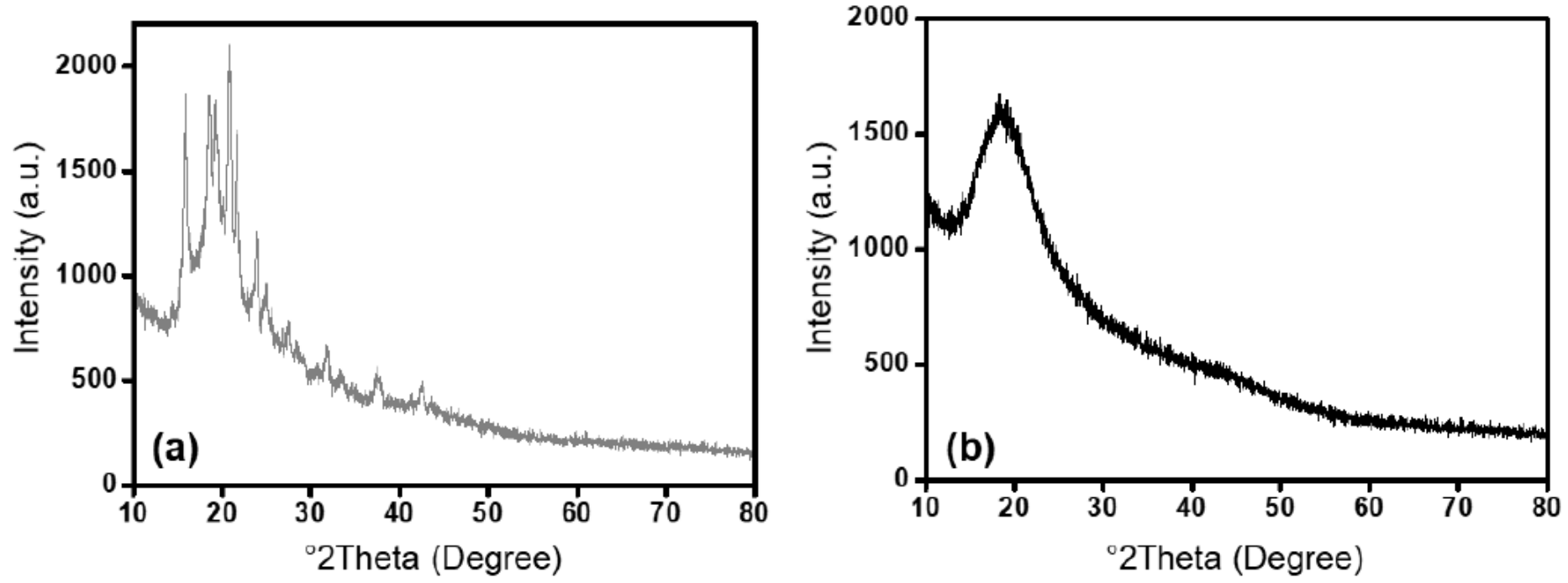

Figure 5

XRD spectra of (a) HES hydrogel and (b) GO-HES nanocomposite hydrogel
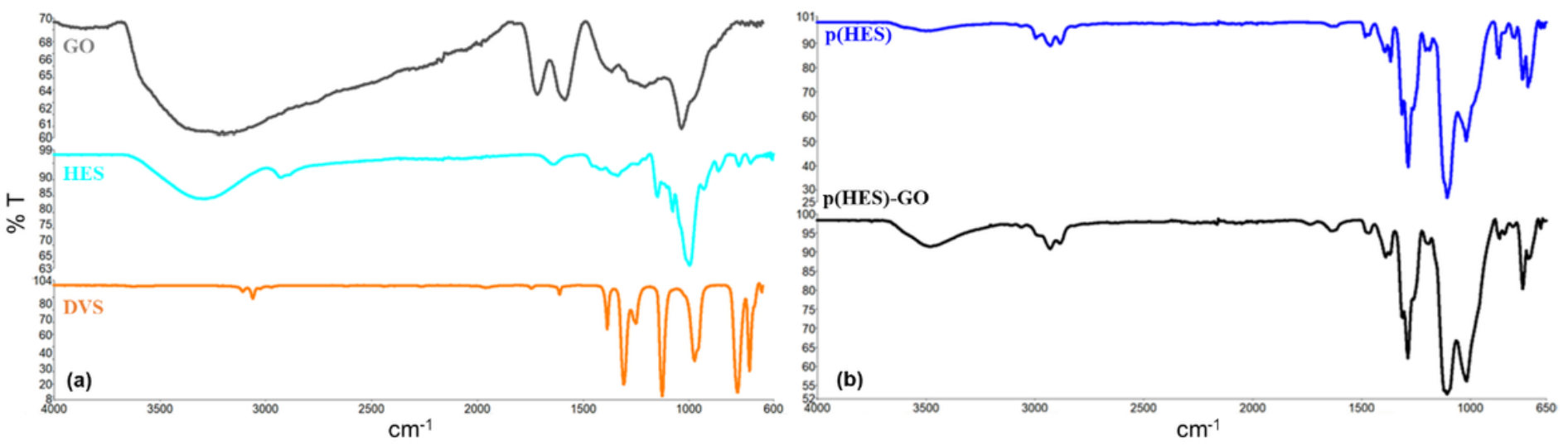
Figure 6

FTIR spectrum of the (a) HES, DVS and GO particle; (b) HES hydrogel and GO-HES nanocomposite hydrogel.
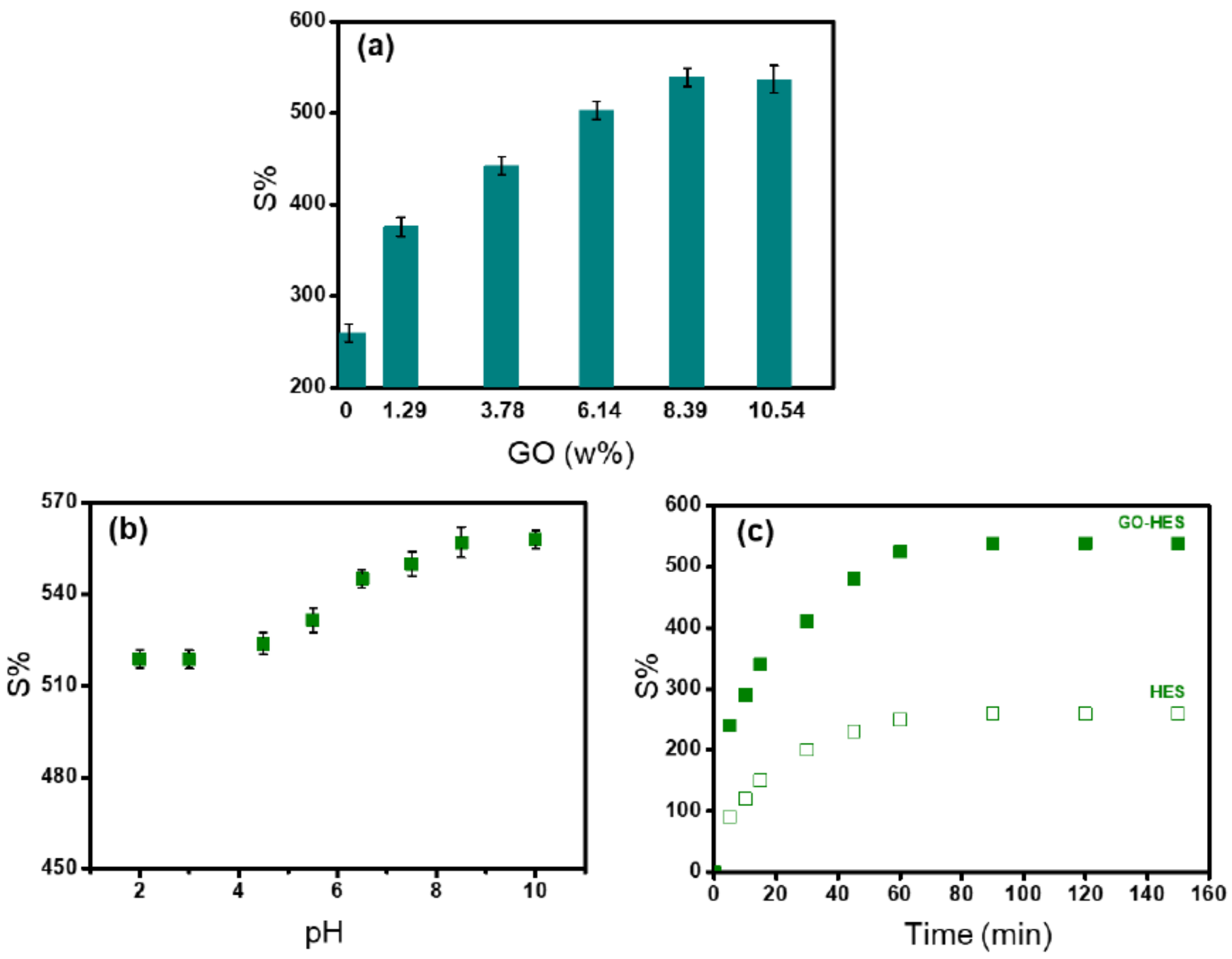

\section{Figure 7}

Swelling curve of (a) GO-HES composite hydrogel with different ratios of GO content in distilled water (b) GO-HES (GO w\%, 8.39) composite hydrogel in various pH solutions (c) HES hydrogel, GO-HES (GO w\%, 8.39) composite hydrogel versus time in distilled water. 

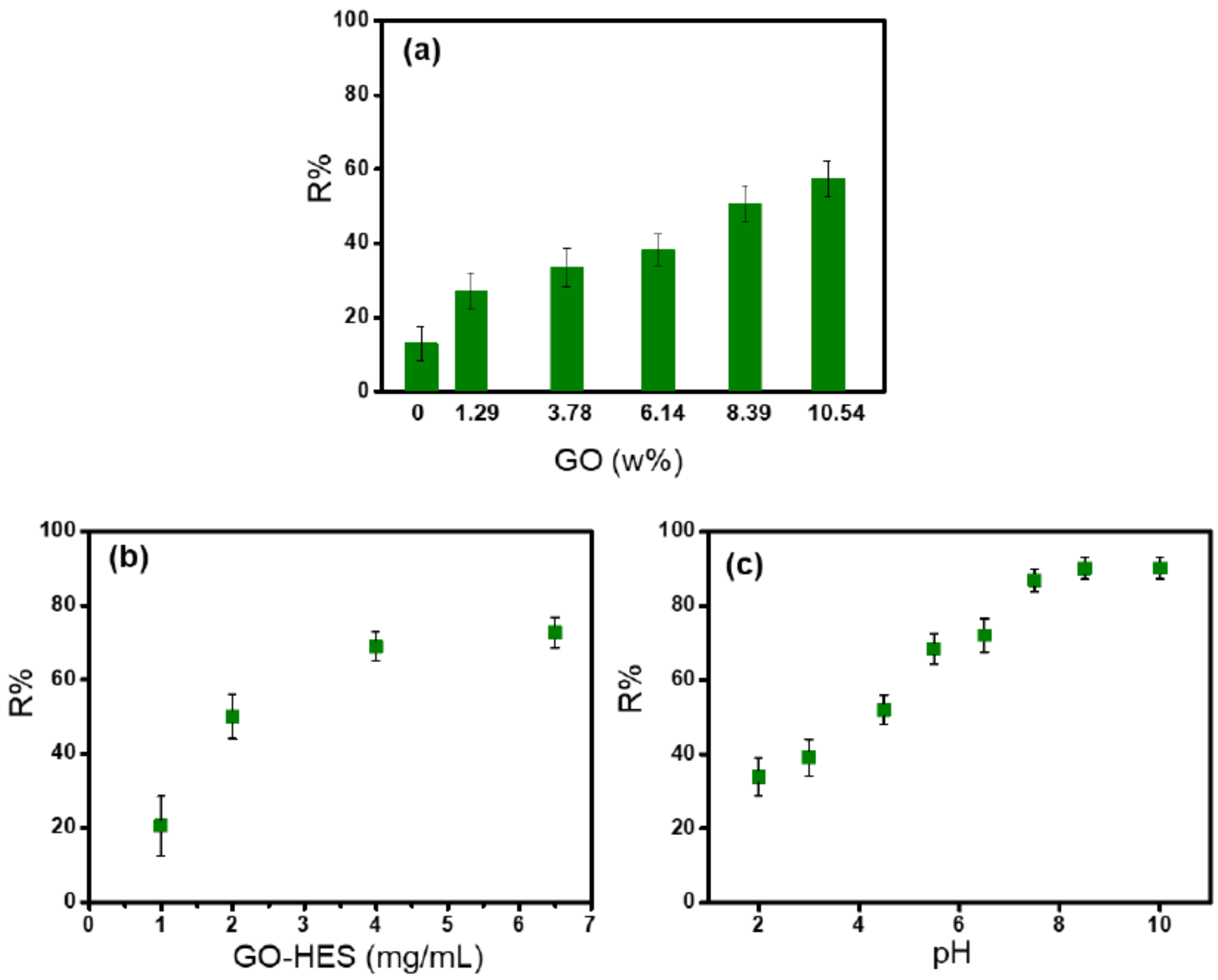

Figure 8

Effect of (a) different ratios of GO content in the hydrogel (b) GO-HES (GO w\%, 8.39) composite hydrogel dosage (c) pH of the MG solution on adsorption capacity of the GO-HES composite hydrogel (GO w\%, 8.39). 


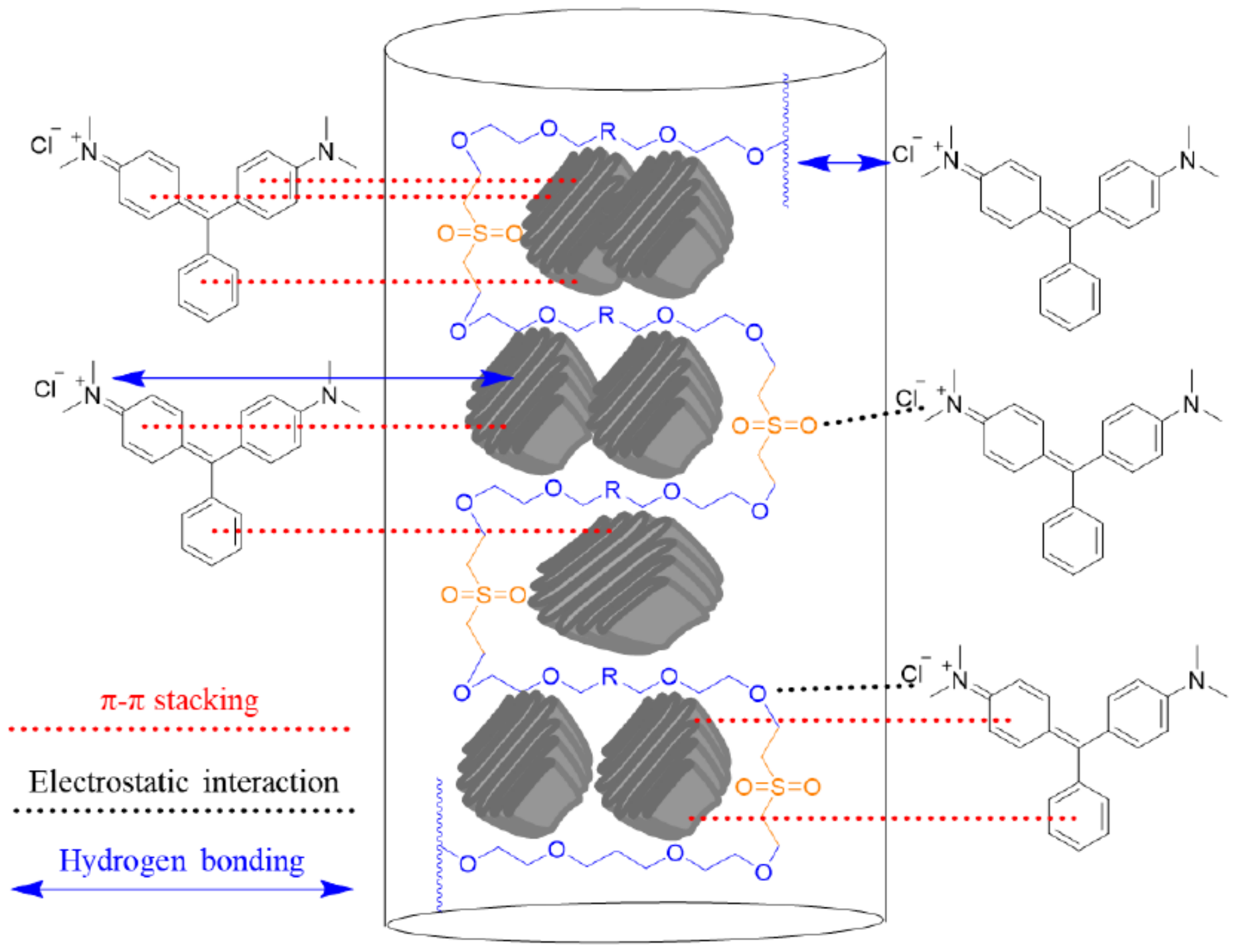

Figure 9

Schematic illustration of the adsorption mechanism between GO-HES composite hydrogel and MG-dye. 

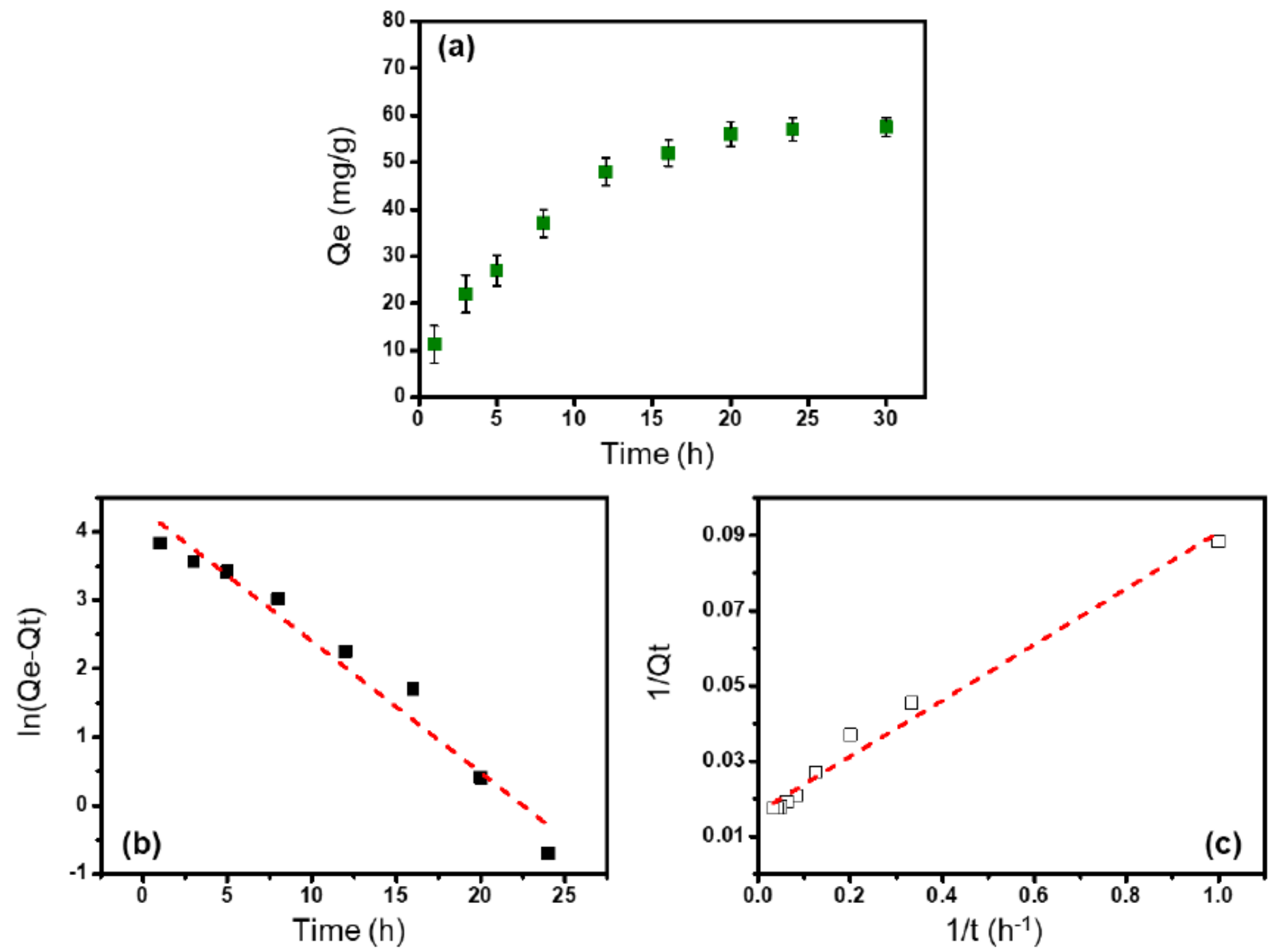

Figure 10

(a) Effect of adsorption time on adsorption capacity of the composite hydrogel (b) Pseudo-first-order and (c) Pseudo-second-order model plots for MG-dye adsorption by composite hydrogel. 

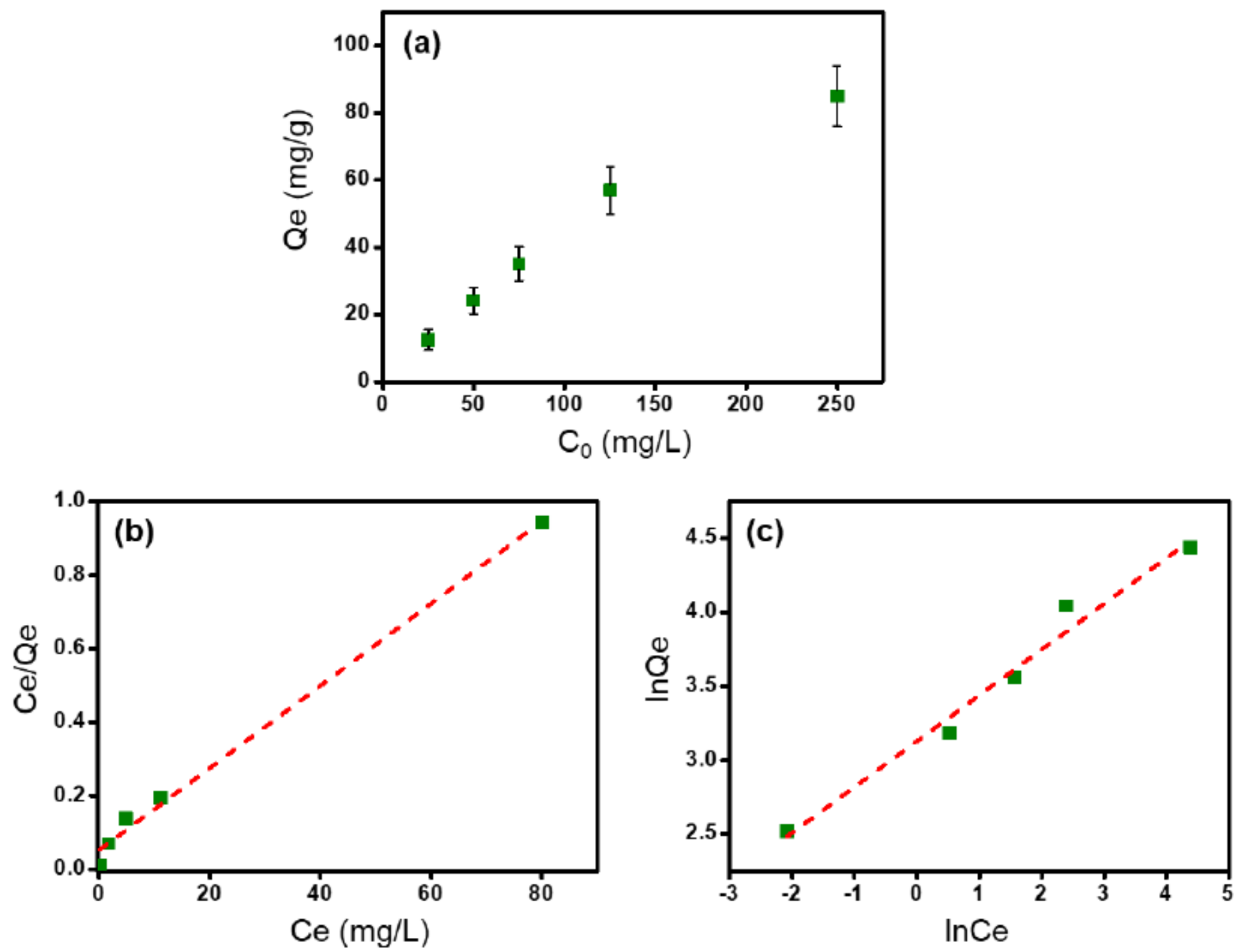

Figure 11

(a) Effect of initial feed concentration of the solution on adsorption capacity of the composite hydrogel,

(b) Langmuir isotherm and (c) Freundlich isotherm model plots for MG-dye adsorption by composite hydrogel. 

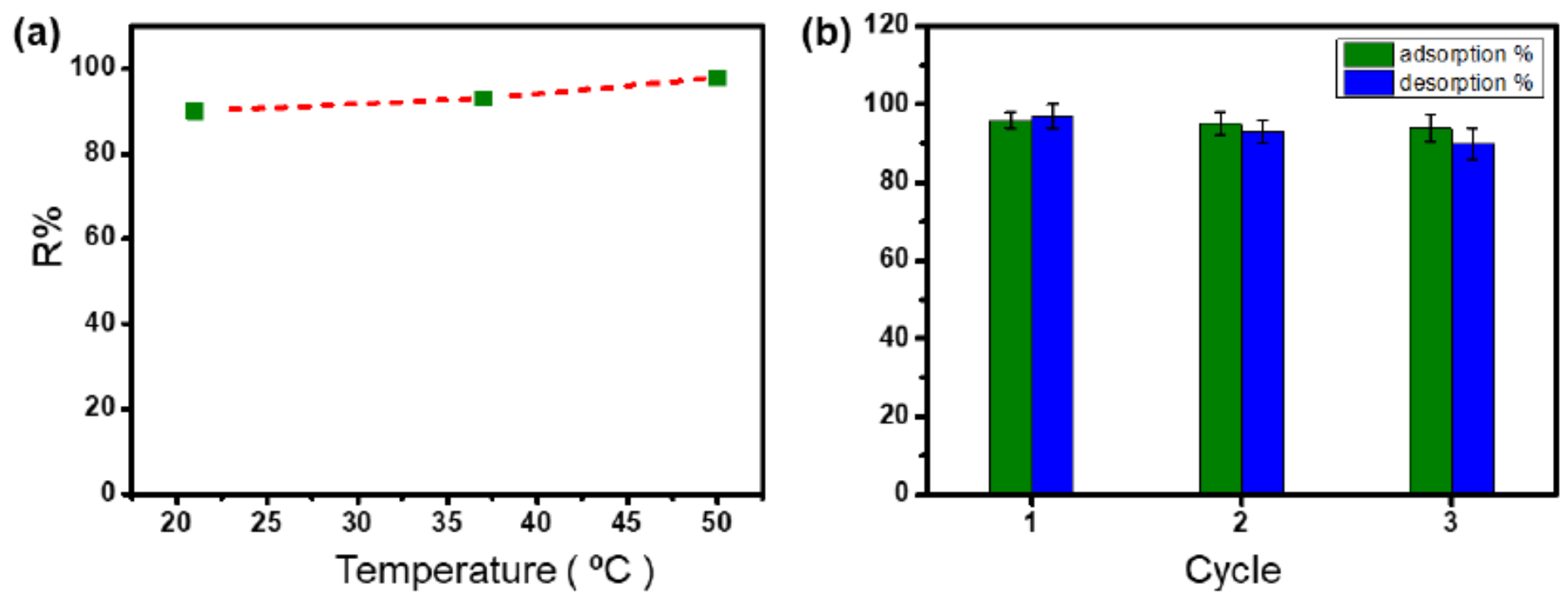

Figure 12

Effect of (a) temperature on adsorption capacity of the composite hydrogel (b) adsorption/desorption cycle of composite hydrogel. 